\title{
The NEI/NCBI dbGAP database: Genotypes and haplotypes that may specifically predispose to risk of neovascular age-related macular degeneration
}

\author{
Hong Zhang ${ }^{2}$, Margaux A Morrison ${ }^{1}$, Andy DeWan' ${ }^{2}$, Scott Adams ${ }^{1}$, \\ Michael Andreoli ${ }^{1}$, Nancy Huynh ${ }^{1}$, Maureen Regan ${ }^{3}$, Alison Brown ${ }^{3}$, \\ Joan W Miller ${ }^{1}$, Ivana K Kim¹, Josephine Hoh ${ }^{* 2}$ and Margaret M DeAngelis*1
}

Address: ${ }^{1}$ Department of Ophthalmology, Harvard Medical School, Massachusetts Eye and Ear Infirmary, Boston, MA, USA, ${ }^{2}$ Department of Epidemiology and Public Health, Yale University School of Medicine, New Haven, CT, USA and ${ }^{3}$ Partner's Healthcare Center for Genetics and Genomics, Harvard Medical School, Cambridge, MA, USA

Email: Hong Zhang - hong.zhang@yale.edu; Margaux A Morrison - margaux_morrison@meei.harvard.edu; Andy DeWan - andrew.dewan@yale.edu; Scott Adams - scott_adams@meei.harvard.edu;

Michael Andreoli - michael_andreoli@meei.harvard.edu; Nancy Huynh - nancy_huynh@meei.harvard.edu; Maureen Regan - MEREGAN@PARTNERS.ORG; Alison Brown - ABROWN13@PARTNERS.ORG;

Joan W Miller - joan_miller@meei.harvard.edu; Ivana K Kim - ivana_kim@meei.harvard.edu; Josephine Hoh* - josephine.hoh@yale.edu; Margaret M DeAngelis* - margaret_deangelis@hms.harvard.edu

* Corresponding authors

Published: 9 June 2008

BMC Medical Genetics 2008, 9:5 I doi: I0.1 |86/|47|-2350-9-5 I
Received: 17 January 2008

Accepted: 9 June 2008

This article is available from: http://www.biomedcentral.com/I47/-2350/9/5 I

(C) 2008 Zhang et al; licensee BioMed Central Ltd.

This is an Open Access article distributed under the terms of the Creative Commons Attribution License (http://creativecommons.org/licenses/by/2.0), which permits unrestricted use, distribution, and reproduction in any medium, provided the original work is properly cited.

\begin{abstract}
Background: To examine if the significantly associated SNPs derived from the genome wide allelic association study on the AREDS cohort at the NEI (dbGAP) specifically confer risk for neovascular age-related macular degeneration (AMD). We ascertained 134 unrelated patients with AMD who had one sibling with an AREDS classification I or less and was past the age at which the affected sibling was diagnosed (268 subjects). Genotyping was performed by both direct sequencing and Sequenom iPLEX system technology. Single SNP analyses were conducted with McNemar's Test (both $2 \times 2$ and $3 \times 3$ tests) and likelihood ratio tests (LRT). Conditional logistic regression was used to determine significant gene-gene interactions. LRT was used to determine the best fit for each genotypic model tested (additive, dominant or recessive).

Results: Before release of individual data, $p$-value information was obtained directly from the AREDS dbGAP website. Of the 35 variants with $P<10^{-6}$ examined, 23 significantly modified risk of neovascular AMD. Many variants located in tandem on Iq32q22 including those in CFH, CFHR4, CFHR2, CFHR5, FI3B, ASPM and ZBTB were significantly associated with AMD risk. Of these variants, single SNP analysis revealed that $C F H$ rs5725I5 was the most significantly associated with AMD risk $\left(P<10^{-6}\right)$. Haplotype analysis supported our findings of single SNP association, demonstrating that the most significant haplotype, GATAGTTCTC, spanning CFH, CFHR4, and CFHR2 was associated with the greatest risk of developing neovascular AMD (P< 10-6). Other than variants on Iq32-q22, only two SNPs, rs92884I0 (MAP2) on 2q34-q35 and rs20I4307 (PLEKHAI/HTRAI) on $10 \mathrm{q} 26$ were significantly associated with AMD status $\left(P=.03\right.$ and $P<10^{-6}$ respectively). After controlling for smoking history, gender and age, the most significant gene-gene interaction appears to be between rs 0801575 (CFH) and rs20I4307 (PLEKHAII HTRAI) $\left(P<10^{-1}\right)$. The best genotypic fit for rs 10801575 and rs20I4307 was an additive model based on LRT. After applying a Bonferonni correction, no other significant interactions were identified between any other SNPs.
\end{abstract}

Conclusion: This is the first replication study on the NEI dbGAP SNPs, demonstrating that alleles on Iq, $2 q$ and $10 q$ may predispose an individual to AMD. 


\section{Background}

Advanced age-related macular degeneration (AMD) is the most common cause of legal blindness in developed countries. Clinically two forms of advanced AMD are recognized: geographic atrophy and neovascular. Geographic atrophy is characterized by a slow progressive degeneration of the retinal pigment epithelium (RPE), resulting in the gradual loss of the photoreceptors. The neovascular form is characterized by the growth of new abnormal blood vessels from beneath the retina that can cause severe and rapid vision loss due to hemorrhage and exudation. It is the neovascular form that is responsible for the majority of debilitating vision loss due to AMD, greatly impairing an individual's ability to read, drive and recognize faces. The burden on public health is significant, as in the U.S. alone, it is predicted that about 3 million individuals over the age of 50 years will have advanced AMD in at least one eye by 2020 [1].

Although the newest treatments for neovascular AMD offer some chance of visual improvement, they require invasive delivery methods, cannot prevent disease, and have limited ability to reverse vision loss. Assessments of an individual's risk of developing advanced AMD are based on ocular findings in those who already have the early stages. Methods are needed for determining which members of the population are at highest risk of vision loss due to AMD prior to the development of any signs of the disease. The identification of genetic variants that could be used as biomarkers would help to predict risk for more advanced stages of AMD and possibly provide new targets for therapeutic or behavioral intervention, thereby reducing or preventing the incidence of this disease.

In an effort to correlate genotypes with advanced AMD clinical phenotypes, the National Eye Institute (NEI) performed a genome wide association study on the Agerelated eye disease study (AREDS) cohort consisting of 395 advanced AMD (both neovascular and geographic atrophy) cases and 198 control subjects. Affymetrix and Illumina $100 \mathrm{~K}$ arrays were used to test for individual SNP (Single Nucleotide Polymorphism) associations [2,3]In the study presented here, we sought to validate these findings in samples from unrelated patients with only neovascular AMD who had one sibling with normal maculae and was past the age at which the affected sibling was diagnosed with neovascular AMD. We employed this approach to examine if some or all of the NEI/NCBI dbGAP SNPs specifically predisposed an individual to AMD by studying subjects with and without the neovascular form of AMD. Our phenotypically well-defined cohort of 268 subjects comprised 134 extremely discordant sibpairs; that is, pairs with one member in the upper $10 \%$ of disease severity (affected sibling) and the other member in the bottom $10-30 \%$ of disease severity (unaffected sib- ling). Mathematical analyses indicate that the evaluation of sibpairs who are extremely discordant for a quantitative, multifactorial trait can be informative for identifying the genetic variants that govern the trait [4]. Many studies have suggested various ways for quantifying AMD but they are not conclusive. However, we know from studies based on prevalence of both early and late AMD that our unaffected siblings likely represent the bottom 10\%-30\% of the population and those with the most severe forms of AMD (geographic atrophy or neovascular AMD) represent the top $10 \%$ with respect to phenotype [5-10].

Moreover, extremely discordant sibpairs can provide a robust alternative study design for finding an association between a genetic variant and a complex disease to using sibpairs with intermediate phenotypes [11] or case-controls study design [12].

We have previously demonstrated that such types of sibpairs can be powerful in identifying the contribution that many genetic variants, even those with a modest effect, along with smoking make simultaneously to AMD susceptibility $[13,14]$. We employed a combination of the Sequenom iPLEX system technology and direct sequencing to genotype 35 variants in order to identify the contribution that the dbGAP allelic risk factors make independently, and in combination, along with smoking to overall risk of developing neovascular AMD.

\section{Results}

We identified all 34 variants we sought to investigate in our extremely discordant sibpair cohort of 268 Caucasian subjects. In our analysis we also included $\mathrm{CFH} \mathrm{Y} 402 \mathrm{H}$ which has been previously analyzed in this cohort [13]. No significant deviations from Hardy-Weinberg equilibrium for any of the variants studied were observed in the unaffected siblings, indicating unlikely contamination of our dataset. For genotype and allele frequencies for each of these SNPs, please see Additional File 1.

The results of both types of McNemar's tests, likelihood ratio tests and resulting $P$ values for all 35 SNPs after controlling for age, gender and smoking are shown in Table 1. The resulting odds ratios, confidence intervals and mode of inheritance resulting from the LRT also appear in Table 1. In addition to the Y402H CFH variant, 23 SNPs were significantly associated with neovascular AMD risk (Table 1). PHASE produced similar results to SNPHAP for diplotype reconstruction so we focused the remainder of our analysis using SNPHAP. Many variants located in tamdem on 1q32-q22 including those in complement Factor $\mathrm{H}$ $(\mathrm{CFH})$, complement factor H-related 4 (CFHR4), complement factor H-related 2 (CFHR2), complement factor $\mathrm{H}$ related 5 (CFHR5), coagulation factor 13 subunit B $(F 13 B)$, abnormal spindle-like microcephaly associated 
(ASPM) and zinc finger and BTB domain containing 41 homolog (ZBTB41) were significantly associated with AMD risk (Table 1). According to LRT, single SNP analysis showed that $C F H$ rs572515 on $1 \mathrm{q} 25$ was the most strongly associated SNP with AMD risk under an additive model. All SNPs analyzed on 1q32-q22 except for $F 13 B$ rs2990510 were significantly associated with neovascular AMD risk using the LRT $(P<.01)$. SNP rs9288410 (MAP2) on 2q35-q34 and SNP rs2014307 on 10q26 PLEKHA1/ HTRA1 were also associated with AMD risk (OR: 1.92; 95\% C.I.: $0.89,4.18 ; P=0.03$ and OR: $0.240 ; 95 \%$ C.I.: $0.11, .52 ; P<10^{-4}$ respectively). According to ENSEMBL [15], SNP rs2014307 is equidistant between the end of PLEKHA1 and the beginning of HTRA1. Single SNP analysis in the 1q32-q22 region was confirmed by demonstrating that the haplotype GATAGTTCTC for alleles spanning $\mathrm{CFH}$, CFHR4, and CFHR2 were associated with the greatest risk of neovascular AMD $\left(P<10^{-6}\right)$. These 9 SNPs, which included the Y402H CFH variant, spanned the 1q31-1q32 region and formed two haplotype blocks (Figure 1a and Figure 1b) that were in linkage disequilibrium $\left(D^{\prime}=0.79\right)$ (Figure 1c) (see Table 2).

Table 3 shows the results for testing interaction, joint effects and main effects of each significantly associated SNP on chromosome 1 with rs2014307 on chromosome 10. After controlling for smoking, age and gender, the resulting P values, odds ratios and 95\% C.I. of each SNP, while controlling for the other SNP, are shown. Almost all of the combinations of SNP pairs tested showed no interaction at 0.05 level of significance, except for rs800292/ rs2014307 and rs3790414/rs2014307. However, neither of these SNP pair combinations was significant after applying a Bonferroni correction. Therefore, no interaction is found in the joint effect and main effect analyses.

The most significant joint effect is observed between rs10801575 and rs2014307 $\left(P<10^{-11}\right)$. The LRT demonstrated that CFH SNP rs10801575 fits best under a dominant model whereas rs 2014307 fits best under an additive model. The main effect for each of these SNPs individually is highly significant (OR: 3.16; 95\% C.I.: 3.16, 7.347; $P<$ 10-4 and OR: 0.26; 95\% C.I.: 0.13, .55; $P<10^{-6}$, respectively).

\section{Discussion}

Inconsistency in replication of findings among studies could possibly be due to population stratification, disease heterogeneity, and/or diagnostic heterogeneity in phenotype among cases [12]. In the study presented here, using phenotypically well defined extremely discordant sibpairs, we were able to confirm the NEI/NCBI dbGAP findings for chromosomes 1,2 and 10 in a Caucasian population (mostly derived from the U.S.) employing a different methodological design [2,3]. Moreover, our findings suggest that specific genetic variants may predispose to the neovascular form of AMD, as the dbGAP data included cases with both neovascularization and geographic atrophy. On the other hand, it could be that our use of the Bonferroni correction was overly stringent (given the LD between many of the SNPs) and this could account for the fact that we only observed a portion of the variants as being significantly associated with neovascular AMD risk. However, in both study designs (NEI and the study presented here) these variants were only examined for association with advanced stages of AMD, and it may be that these variants are also associated with the early forms of AMD as well. Further, we were able to demonstrate the risk of AMD conferred by the joint effect of these SNPs while controlling for smoking history, age and gender. The most significant joint effect was between rs 10801575 (CFH) and rs2014307 (PLEKHA1/HTRA1) ( $P$ $<10^{-11}$ ). After controlling for the effect of each SNP with respect to the other, it was evident that this joint effect was due to the significant assocation of SNP rs2014307 with AMD risk, as the $p$ value was greater for the PLEKHA1/ HTRA1 SNP $\left(P<10^{-6}\right)$ than it was for CFH SNP rs10801575, $\left(P<10^{-4}\right)$. While these findings support the contribution of chromosome 1q22-q32, they also demonstrate that the 10q26 region is likely more stongly associated with neovascular AMD risk [13,16-18]. It may be that the dbGAP variants we analyzed on chromosomes $3 p, 4 q, 11 q$ and $12 q$ predispose an individual to the geographic atrophic subytpe. Whether or not these variants represent true disease causing variants or are in high $\mathrm{LD}$ with the susceptibilily allele remains to be determined. We demonstrated that variants in the complement pathway genes CFH, CFHR2, CFHR4 and CFHR5 are significantly associated with AMD risk, however variants in these genes may not be independent factors in the pathophysiology of AMD due to the high LD throughout the 1q25-1q32 region [19-25].

We also demonstrated that significantly associated variants in F13B, ASPM, MAP2 and ZBTB41 point to other pathways yet to be studied in AMD etiology. F13B is the noncatalytic subunit of coagulation factor 13 , which upon activation by thrombin, functions to covalently cross-link fibrin, making a clot mechanically stronger and more resistant to fibrinolysis [26]. F13B is composed of 641 amino acids, divided into 10 tandem repeats, which is characteristic of the complement activation system regulatory proteins [27] There is also a structural similarity between $F 13 B$ and $C F H[28,29]$. Both ASPM and MAP2 play a critical role during neurogenesis. ASPM regulates brain growth and mutations in this gene were shown to be associated with microcephaly [30-32]. Further ASPM has been implicated in tumor cell proliferation and growth [33] MAP2 stabilizes and interacts with microtubules during the growth, differentiation, and development of neu- 


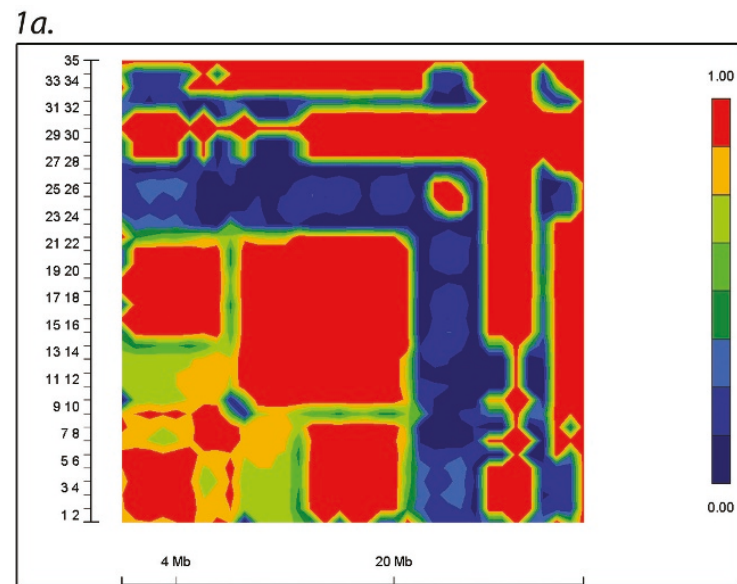

$1 c$.

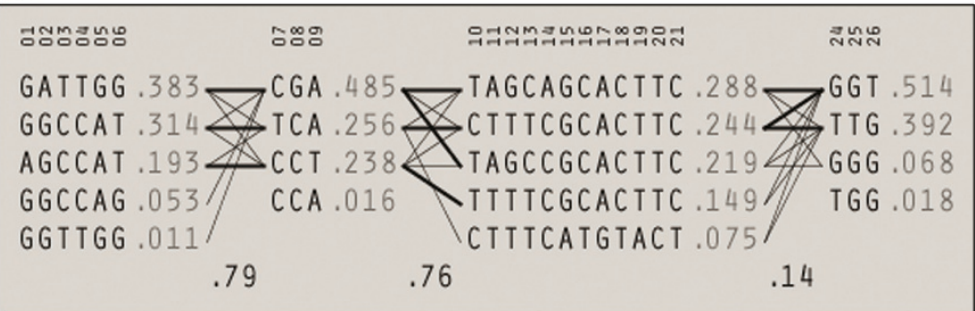

16.

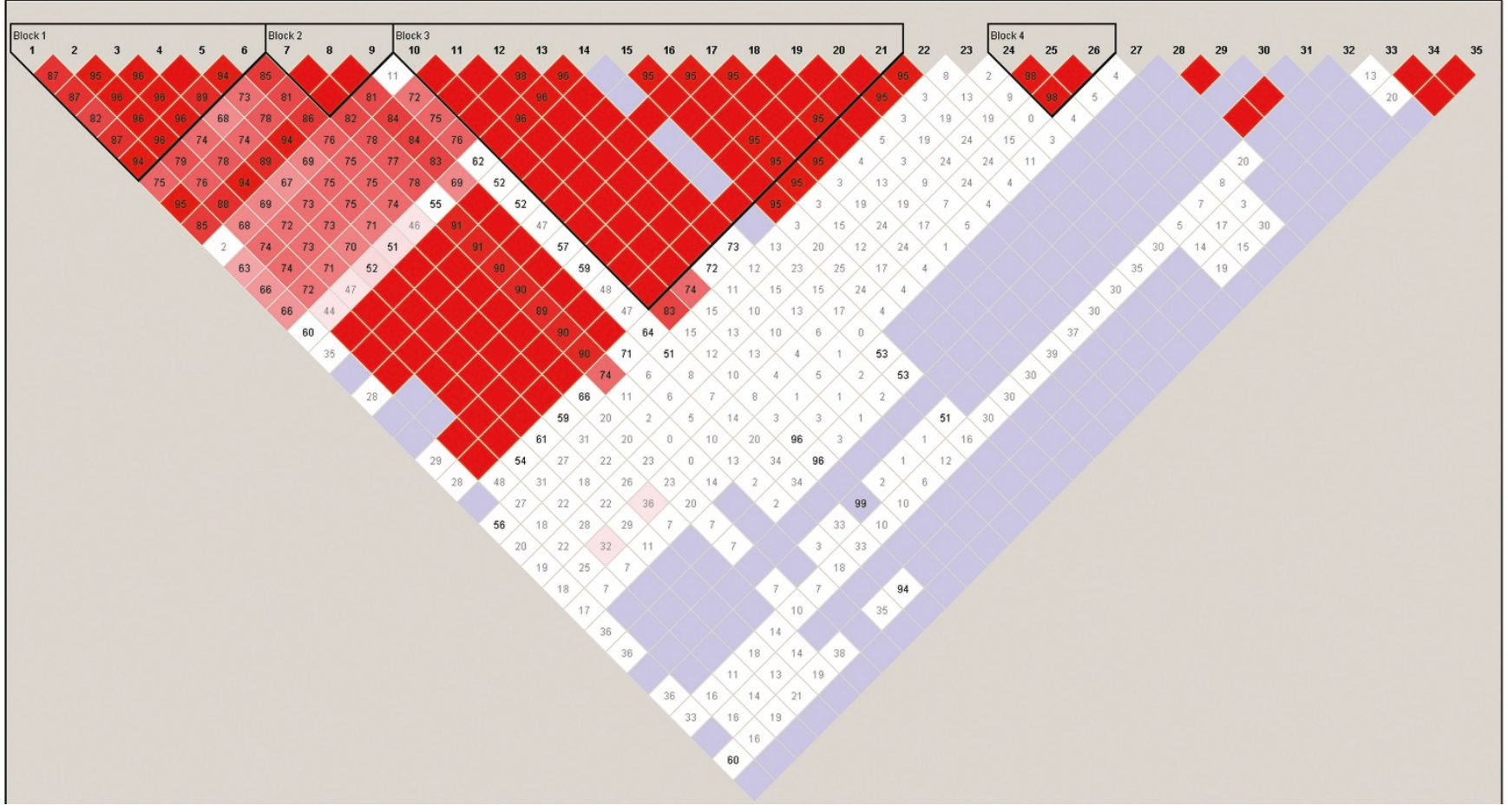

Figure I

Ia. Linkage disequilibrium ( $\left.D^{\prime}\right)$ between the genotyped SNPs as shown in a heat map. SNPs encompassing the Iq22-q32 region are represented by 3 distinct haplotype blocks. The more red the color, the higher the LD which is indicated by the gradient bar to the right of the LD plot. I b. Linkage disequilibrium ( $\left.D^{\prime}\right)$ between the genotyped SNPs as shown in an LD plot. I c. Haplotypes Haplotypes of SNPs together with estimated frequencies are shown. The values of multi-allelic D' $(.79, .76$, and .14) reflect the level of recombination between adjacent blocks. Abbreviations: bp, base pairs; SNP, Single Nucleotide Polymorphism; Linkage disequilibrium ( $\left.D^{\prime}\right)$.

rons [34,35]. Further, ZBTB41 proteins are transcription regulators, functioning in a wide range of processes, including development, differentiation, and oncogenesis [36,37]. ZBTB41 proteins also play an important role in the hematopoietic system, particularly in T cell development and function [38].

\section{Conclusion}

In summary, this is the first report to confirm association of neovascular AMD risk variants obtained from the NEI/ NCBI dbGAP database. Moreover, we show that specific variants may predispose to only the neovascular form of $\mathrm{AMD}$, and in agreement with others, show that the $10 \mathrm{q} 26$ 
Table I: Single SNP Analysis

\begin{tabular}{|c|c|c|c|c|c|c|c|}
\hline SNP & Gene* & Location* & $\begin{array}{l}2 \times 2 \text { McNemar's } \\
\text { test } p \text {-value }\end{array}$ & $\begin{array}{l}3 \times 3 \text { McNemar's } \\
\text { test } p \text {-value }\end{array}$ & $\begin{array}{l}\text { Likelihood Ratio } \\
\text { Test } p \text {-value }\end{array}$ & $\begin{array}{l}\text { Odds Ratio ( } 95 \% \\
\text { C.I.) of most likely } \\
\text { mode of inheritance }\end{array}$ & $\begin{array}{l}\text { Likelihood Ratio } \\
\text { Test Model }\end{array}$ \\
\hline rs800292 & CFH & Iq32 & 0.0005 & $1.6766 \mathrm{E}-05$ & 0.0020 & $0.295(0.126-0.693)$ & Additive \\
\hline rs5725I5 & $\mathrm{CFH}$ & $1 \mathrm{q} 32$ & $1.1422 \mathrm{E}-06$ & $2.177 \mid \mathrm{E}-09$ & $7.00 \mid 2 E-07$ & $4.619(2.288-9.326)$ & Additive \\
\hline rs7529589 & $\mathrm{CFH}$ & $1 \mathrm{q} 32$ & 0.0003 & I.6852E-05 & $1.2034 \mathrm{E}-05$ & $8.403(2.670-26.442)$ & Recessive \\
\hline rs1061170 & $\mathrm{CFH}$ & $1 q 32$ & 0.0002 & $3.982 \mid \mathrm{E}-05$ & $1.9045 \mathrm{E}-05$ & $7.382(2.495-21.838)$ & Recessive \\
\hline rs/2038333 & $\mathrm{CFH}$ & $1 q 32$ & 0.0001 & I.7989E-06 & $8.3182 \mathrm{E}-06$ & $3.151(1.707-5.819)$ & Recessive \\
\hline rs203674 & $\mathrm{CFH}$ & $1 \mathrm{q} 32$ & $5.7447 \mathrm{E}-06$ & $5.0608 \mathrm{E}-08$ & $4.3995 \mathrm{E}-06$ & $3.914(2.020-7.585)$ & Additive \\
\hline rs 10801575 & $\sim \mathrm{CFH}$ & $\sim 1 q 32$ & 0.0304 & 0.0315 & 0.0108 & $0.370(0.174-0.785)$ & Dominant \\
\hline rsl853883 & CFHR4 & $1 \mathrm{q} 32$ & 0.0001 & $6.9750 \mathrm{E}-06$ & 0.0003 & $2.687(1.519-4.751)$ & Additive \\
\hline rs37904I4 & CFHR2 & $\mid q 31-q 32.1$ & 0.0018 & 0.0002 & 0.0137 & $0.424(0.206-0.876)$ & Additive \\
\hline rs 1759016 & CFHR5 & Iq22-q23 & 0.0092 & 0.0037 & 0.0092 & $0.465(0.262-0.827)$ & Additive \\
\hline rs 10922152 & CFHR5 & $1 q 22-q 23$ & 0.0007 & 0.0001 & 0.0014 & $0.434(0.258-0.730)$ & Additive \\
\hline rs 10922153 & CFHR5 & Iq22-q23 & 0.0002 & $1.0290 \mathrm{E}-05$ & 0.0004 & $0.389(0.224-0.677)$ & Additive \\
\hline rs6663083 & $?$ & $|q 3|-\mid q 32$ & 0.0003 & I.6704E-05 & 0.0008 & $0.419(0.248-0.707)$ & Additive \\
\hline rs2990510 & $\mathrm{FI} 3 \mathrm{~B}$ & $|q 3|-q 32.1$ & 0.0438 & 0.0395 & 0.1003 & $2.462(0.80 I-7.57 \mathrm{I})$ & Recessive \\
\hline rs6003 & $\mathrm{FI} 3 \mathrm{~B}$ & $1 q 31-q 32.1$ & 0.0153 & 0.0022 & 0.0025 & $0.162(0.04 \mid-0.63 I)$ & Additive \\
\hline$r s|4| 2632$ & $?$ & $|q 31-| q 32$ & 0.0153 & 0.0022 & 0.0030 & $0.165(0.042-0.645)$ & Additive \\
\hline$r s|4| 263 \mid$ & $?$ & $|q 31-| q 32$ & 0.0098 & 0.0005 & 0.0013 & $0.110(0.022-0.557)$ & Additive \\
\hline rs 12677 & ASPM & $|q 3|$ & 0.0098 & 0.0005 & 0.0019 & $0.127(0.026-0.609)$ & Additive \\
\hline rs49I5337 & ASPM & $|q 3|$ & 0.0614 & 0.0233 & 0.0067 & $0.182(0.045-0.740)$ & Additive \\
\hline rs|88899| & ASPM & $|q 3|$ & 0.0244 & 0.0051 & 0.0044 & $0.175(0.044-0.696)$ & Additive \\
\hline rs6677082 & ASPM & $|q 3|$ & 0.0244 & 0.0051 & 0.0048 & $0.175(0.044-0.695)$ & Additive \\
\hline rs6656448 & ZBTB4I & $|q 3| .3$ & 0.0218 & 0.0054 & 0.0042 & $0.209(0.063-0.694)$ & Additive \\
\hline rs9288410 & MAP2 & $2 q 34-q 35$ & 0.5563 & 0.3721 & 0.0294 & $1.923(0.885-4.179)$ & Recessive \\
\hline rs304039 & ITPRI & $3 p 26-p 25$ & 0.6774 & 0.7070 & 0.1035 & $1.943(0.858-4.396)$ & Recessive \\
\hline rs30404I & ITPRI & $3 p 26-p 25$ & 0.5896 & 0.4206 & 0.1035 & $1.943(0.858-4.396)$ & Recessive \\
\hline rs1038639 & ITPRI & $3 p 26-p 25$ & 1.0000 & 0.9062 & 0.4345 & $0.731(0.332-1.610)$ & Dominant \\
\hline rs 1447338 & $?$ & $4 q 34-4 q 35$ & 0.5419 & 0.4856 & 0.2949 & $1.350(0.730-2.497)$ & Additive \\
\hline rs7090030 & ADD3 & $10 q 24.2-q 24.3$ & 1.0000 & 1.0000 & 0.5834 & $0.485(0.035-6.710)$ & Additive \\
\hline rsIII 94995 & ADD3 & $10 q 24.2-q 24.3$ & 1.0000 & 1.0000 & 0.5834 & $0.485(0.035-6.710)$ & Additive \\
\hline rsIII94996 & ADD3 & $10 q 24.2-q 24.3$ & 1.0000 & 1.0000 & 0.9217 & $0.88 \mid(0.07|-| 0.862)$ & Additive \\
\hline rsIII9500I & ADD3 & $10 q 24.2-q 24.3$ & 1.0000 & 1.0000 & 1.0000 & $0.485(0.035-6.715)$ & Additive \\
\hline rs2014307 & PLEKHAI/HTRAI & $10 q 26$ & $6.6872 \mathrm{E}-06$ & $8.1056 \mathrm{E}-07$ & $3.7092 \mathrm{E}-05$ & $0.240(0.111-0.520)$ & Additive \\
\hline rs949252 & GPRI52 & $1|q| 3.1$ & 0.4795 & 0.4795 & 0.1979 & $2.006(0.115-35.135)$ & Dominant \\
\hline rs7|24630 & TMEMI 34 & $1|q| 3.1$ & 0.4795 & 0.0000 & 0.3864 & $1.004 \mathrm{E}-07(0.000-\operatorname{lnf})$ & Additive \\
\hline rsII57522I & STAT2 & $12 q 13-12 q 14$ & 1.0000 & 1.0000 & 0.4358 & $2.740(0.204-36.835)$ & Additive \\
\hline
\end{tabular}

Abbreviations: SNP, single nucleotide polymorphism; C.I., confidence interval.

* Gene and location of each SNP determined using ENSEMBL [15].

region is more strongly associated with neovascular AMD risk than $1 \mathrm{q}$.

\section{Methods}

\section{Patient population}

The protocol was reviewed and approved by the Institutional Review Boards at the Massachusetts Eye \& Ear Infirmary (MEEI), Boston, Massachusetts and the William Beaumont Hospital, Royal Oak, Michigan and conforms to the tenets of the Declaration of Helsinki. Eligible patients were enrolled in this study after they gave informed consent either in person, over the phone, or through the mail, before answering questions to a standardized questionnaire and donating 10 to $50 \mathrm{ml}$ of venous blood.

Details of the recruitment of patients and their siblings are described elsewhere $[14,39]$. In brief, all index patients were aged 50 years or older and had the neovascular form of AMD in at least one eye, defined by subretinal hemor- rhage, fibrosis, or fluorescein angiographic presence of neovascularization documented at the time of, or prior to, enrollment in the study. Patients whose only exudative finding was a retinal pigment epithelium detachment were excluded because this finding may not represent definite neovascular AMD and, therefore, the severe phenotype we sought. Patients with signs of pathologic myopia, presumed ocular histoplasmosis syndrome, angioid streaks, choroidal rupture, any hereditary retinal diseases other than $\mathrm{AMD}$, and previous laser treatment due to retinal conditions other than AMD were also excluded.

The unaffected siblings had normal maculae at an age older than that at which the index patient was first diagnosed with neovascular AMD. Normal maculae (defined as the zone centered at the foveola and extending 2 disc diameters, or 3000 microns, in radius) fulfilled the following criteria: 0-5 small drusen (all less than 63 microns in diameter), no pigment abnormalities, no geographic atrophy, and no neovascularization (as defined previ- 
Table 2: Legend of Figure I.

\begin{tabular}{|c|c|c|c|}
\hline ID & rs number & Chromosome & Position (bp) \\
\hline I & rs800292 & I & 169751219 \\
\hline 2 & rs5725I5 & 1 & 169755247 \\
\hline 3 & rs7529589 & I & 169767262 \\
\hline 4 & rs106II70 & 1 & 169768220 \\
\hline 5 & rs 12038333 & I & $16978 \mid 422$ \\
\hline 6 & rs 203674 & I & |6979360| \\
\hline 7 & rs1080I575 & I & 169966624 \\
\hline 8 & rsl853883 & I & |6999566| \\
\hline 9 & rs37904I4 & 1 & 170045770 \\
\hline 10 & rsl759016 & I & I 70077967 \\
\hline II & rs 10922152 & I & 170088475 \\
\hline 12 & rs 10922153 & I & 170104084 \\
\hline 13 & rs6663083 & I & 170106129 \\
\hline 14 & rs29905I0 & I & $170|46| 27$ \\
\hline 15 & rs 6003 & I & $170 \mid 56490$ \\
\hline 16 & rs 1412632 & 1 & 170162337 \\
\hline 17 & rs|4|263| & I & 170162706 \\
\hline 18 & rs I 2677 & I & $170 \mid 78842$ \\
\hline 19 & rs4915337 & I & $1702 \mid 7004$ \\
\hline 20 & rs|88899| & 1 & 170236289 \\
\hline 21 & rs6677082 & 1 & 170238000 \\
\hline 22 & rs6656448 & I & 170268765 \\
\hline 23 & rs9288410 & 2 & 204266059 \\
\hline 24 & rs304039 & 3 & 4490512 \\
\hline 25 & rs30404I & 3 & 4491054 \\
\hline 26 & rsl038639 & 3 & 4500754 \\
\hline 27 & rs|447338 & 4 & 178374405 \\
\hline 28 & rs7090030 & 10 & 105592344 \\
\hline 29 & rsIII94995 & 10 & 105619802 \\
\hline 30 & rsll194996 & 10 & 105621397 \\
\hline 31 & rsll|9500I & 10 & 105626325 \\
\hline 32 & rs20I4307 & 10 & II 7949887 \\
\hline 33 & rs949252 & 11 & 66975485 \\
\hline 34 & rs7124630 & 11 & 66997187 \\
\hline 35 & rsII57522I & 12 & 56407497 \\
\hline
\end{tabular}

ously [14,39]; AMD "category 1 " or less on the AREDS scale). Disease status of every participant was confirmed by at least two of the investigators by evaluation of fundus photographs or fluorescein angiograms except when one of the investigators directly examined an unaffected sibling during a home visit ( $\mathrm{n}=4$ cases). Subject characteristics of our extremely discordant sibpair population are presented in Table 4.

Additionally, we administered a standardized questionnaire to all eligible participants in person or over the phone to ascertain smoking exposure, with the age of the index patient at the time of the fundus photographs as our cutoff reference age for smoking exposure for both members in a sibship. In most cases, the diagnosis of AMD was made simultaneously with the diagnosis of neovascular AMD. If a participant ever smoked, we recorded the age when they started smoking, the age when they quit smoking (if they did quit), and the number of packs of ciga- rettes smoked per day, on average. Based on the responses, the number of pack-years of cigarettes smoked was calculated for each smoker. Participants who smoked less than 100 cigarettes during their lifetime (i.e., less than $1 / 73$ of a pack-year) were categorized as having never smoked. A pack-year was defined as one pack of cigarettes per day for one year, with one pack defined as twenty cigarettes.

\section{Genotyping Analysis}

For both the Sequenom iPLEX system technology and direct sequencing protocols, leukocyte DNA was either purified by using standard phenol-chloroform or DNAzol (Invitrogen Corporation, Carlsbad, California) extraction protocols.

Multiplex PCR assays were designed using Sequenom SpectroDESIGNER software (version 3.0.0.3) by inputting sequence containing the SNP site and 100 bp of flanking sequence on either side of the SNP. Briefly, 10 ng genomic DNA was amplified in a $5 \mathrm{ul}$ reaction containing $1 \times$ HotStar Taq PCR buffer (Qiagen), $1.625 \mathrm{mM} \mathrm{MgCl}_{2}, 500 \mathrm{uM}$ each dNTP, $100 \mathrm{nM}$ each PCR primer, $0.5 \mathrm{U}$ HotStar Taq (Qiagen). The reaction was incubated at $94^{\circ} \mathrm{C}$ for $15 \mathrm{~min}$ utes followed by 45 cycles of $94^{\circ} \mathrm{C}$ for 20 seconds, $56^{\circ} \mathrm{C}$ for 30 seconds, $72^{\circ} \mathrm{C}$ for 1 minute, followed by 3 minutes at $72^{\circ} \mathrm{C}$. Excess $\mathrm{dNTPs}$ were then removed from the reaction by incubation with $0.3 \mathrm{U}$ shrimp alkaline phosphatase (USB) at $37^{\circ} \mathrm{C}$ for 40 minutes followed by 5 minutes at $85^{\circ} \mathrm{C}$ to deactivate the enzyme. Single primer extension over the SNP was carried out in a final concentration of between $0.625 \mathrm{uM}$ and $1.5 \mathrm{uM}$ for each extension primer (depending on the mass of the probe), iPLEX termination mix (Sequenom) and 1.35 U iPLEX enzyme (Sequenom) and cycled using a two-step 200 short cycles program; $94^{\circ} \mathrm{C}$ for 30 seconds followed by 40 cycles of $94^{\circ} \mathrm{C}$ for 5 seconds, 5 cycles of $52^{\circ} \mathrm{C}$ for 5 seconds, and $80^{\circ} \mathrm{C}$ for 5 seconds, then $72^{\circ} \mathrm{C}$ for 3 minutes. The reaction was then desalted by addition of $6 \mathrm{mg}$ cation exchange resin followed by mixing and centrifugation to settle the contents of the tube. The extension product was then spotted onto a 384 well spectroCHIP before being flown in the MALDI-TOF mass spectrometer. Data was collected, real time, using SpectroTYPER Analyzer 3.3.0.15, SpectraAQUIRE 3.3.1.1 and SpectroCALLER 3.3.0.14 (Sequenom). Additionally, to ensure data quality, genotypes for each subject were also checked manually.

Six of the dbGAP SNPs (rs11575221, rs949252, rs11194995, rs6656448, rs12677, rs6003) were not amenable to genotyping by the Sequenom iPLEX system technology and thus were directly sequenced. Oligonucleotide primers were selected using the Primer3 program [40] to encompass the entire coding region and flanking intronic sequences except in the case of an intronic SNP 
Table 3: Pairwise SNP Analysis

\begin{tabular}{|c|c|c|c|c|c|c|}
\hline SNP & Interaction & $\begin{array}{l}\text { Joint effect of SNP and } \\
\text { rs20 I } 4307\end{array}$ & $\begin{array}{l}\text { Effect of SNP, } \\
\text { controlling for } \\
\text { rs2014307 }\end{array}$ & $\begin{array}{l}\text { Odds Ratio ( } 95 \% \\
\text { C.I.) }\end{array}$ & $\begin{array}{l}\text { Effect of rs20 I } 4307 \text {, } \\
\text { controlling for SNP }\end{array}$ & $\begin{array}{l}\text { Odds Ratio ( } 95 \% \\
\text { C.I.) }\end{array}$ \\
\hline rs800292 & 0.034082688 & $1.51 \mathrm{E}-06$ & 0.0005 & $0.369(0.151-0.899)$ & 0.0193 & $0.27 I(0.122-0.603)$ \\
\hline rs5725I5 & 0.560883637 & $2.03 \mathrm{E}-10$ & 0.0003 & $4.817(2.236-10.379)$ & $3.7602 \mathrm{E}-06$ & $0.233(0.096-0.562)$ \\
\hline rs7529589 & 0.454600765 & 7.27E-09 & 0.0007 & $7.861(2.283-27.066)$ & 0.0001 & $0.260(0.112-0.605)$ \\
\hline rs 1061170 & 0.597380515 & $2.22 \mathrm{E}-08$ & 0.0007 & $6.831(2.113-22.079)$ & 0.0002 & $0.258(0.111-0.600)$ \\
\hline rs 12038333 & 0.393546389 & $4.22 \mathrm{E}-08$ & 0.0006 & $2.884(1.512-5.503)$ & 0.0004 & $0.272(0.121-0.609)$ \\
\hline rs203674 & 0.463309999 & $2.68 \mathrm{E}-09$ & 0.0007 & $3.721(1.847-7.496)$ & 0.0001 & $0.256(0.109-0.603)$ \\
\hline rs10801575 & 0.808299262 & I.49E-II & $4.0182 \mathrm{E}-05$ & $0.309(0.135-0.710)$ & 0.0078 & $0.194(0.079-0.475)$ \\
\hline rsl853883 & 0.760773267 & $9.31 \mathrm{E}-08$ & 0.0004 & $2.448(I .355-4.42 I)$ & 0.0021 & $0.263(0.117-0.589)$ \\
\hline rs37904I4 & 0.088493626 & $2.96 \mathrm{E}-06$ & 0.0001 & $0.463(0.213-1.004)$ & 0.0411 & $0.252(0.115-0.554)$ \\
\hline rs1759016 & $0.87384677 \mid$ & $9.04 \mathrm{E}-07$ & 0.0001 & $0.490(0.266-0.902)$ & 0.0244 & $0.246(0.111-0.545)$ \\
\hline rs 10922152 & 0.876195836 & I.15E-07 & 0.0002 & $0.484(0.282-0.831)$ & 0.0056 & $0.245(0.107-0.558)$ \\
\hline rs 10922153 & 0.518399094 & 2.99E-09 & 0.0006 & $0.413(0.232-0.736)$ & 0.0052 & $0.259(0.110-0.606)$ \\
\hline rs6663083 & 0.989583181 & $6.89 \mathrm{E}-08$ & 0.0001 & $0.443(0.258-0.761)$ & 0.0015 & $0.223(0.095-0.523)$ \\
\hline rs2990510 & 0.487660055 & $4.62 \mathrm{E}-06$ & $3.9350 \mathrm{E}-05$ & $2.894(0.874-9.585)$ & 0.0684 & $0.222(0.099-0.499)$ \\
\hline rs6003 & 0.454199074 & 4.15E-07 & 0.0001 & $0.151(0.035-0.649)$ & 0.0048 & $0.222(0.098-0.501)$ \\
\hline rs $14 \mid 2632$ & 0.396769175 & $5.6 \mid \mathrm{E}-07$ & 0.0001 & $0.164(0.038-0.697)$ & 0.0066 & $0.226(0.100-0.509)$ \\
\hline rs|4|263| & 0.64561949 & $2.26 \mathrm{E}-07$ & 0.0001 & $0.113(0.021-0.592)$ & 0.0025 & $0.234(0.104-0.527)$ \\
\hline rs 12677 & 0.500827762 & $5.73 \mathrm{E}-07$ & 0.0002 & $0.132(0.025-0.707)$ & 0.0068 & $0.239(0.108-0.528)$ \\
\hline rs4915337 & $0.3|372733|$ & $1.02 \mathrm{E}-06$ & 0.0001 & $0.176(0.040-0.782)$ & 0.0127 & $0.239(0.108-0.528)$ \\
\hline rs 188899| & 0.454199074 & 4.15E-07 & 0.0001 & $0.151(0.035-0.649)$ & 0.0048 & $0.222(0.098-0.501)$ \\
\hline rs6677082 & 0.454199074 & $4.15 \mathrm{E}-07$ & $4.8640 \mathrm{E}-05$ & $0.151(0.035-0.649)$ & 0.0048 & $0.222(0.098-0.501)$ \\
\hline rs6656448 & 0.707806912 & I.10E-06 & 0.0001 & $0.224(0.062-0.809)$ & 0.0136 & $0.236(0.106-0.525)$ \\
\hline
\end{tabular}

Abbreviations: SNP, Single Nucleotide Polymorphism; C.I., Confidence Interval.

(rs6656448) where at least 100 base pairs on either side of the variant was sequenced and analyzed (Table 5).

For all amplicons, the polymerase chain reaction (PCR) was used to amplify genomic DNA fragments from $20 \mathrm{ng}$ of leukocyte DNA in a solution of $10 \times$ PCR buffer containing $25 \mathrm{mM}$ of $\mathrm{MgCl}_{2}, 0.2 \mathrm{mM}$ each of dATP, dTTP, dGTP, and dCTP, and 0.5 units of Taq DNA polymerase (USB Corporation, Cleveland, $\mathrm{OH}$ ). $5 \mathrm{M}$ Betaine was added to each PCR (Sigma-Aldrich, St. Louis, MO), except for the reactions containing primers used to analyze rs 12677 and rs6003. The temperatures used during the polymerase chain reaction were as follows: $95^{\circ} \mathrm{C}$ for 5 minutes followed by 35 cycles of $58^{\circ} \mathrm{C}$ for 30 seconds, $72^{\circ} \mathrm{C}$ for 30 seconds and $95^{\circ} \mathrm{C}$ for 30 seconds, with a final annealing at $58^{\circ} \mathrm{C}$ for 1.5 minutes and extension of $72^{\circ} \mathrm{C}$ for 5 minutes. For sequencing reactions, PCR products were digested according to manufacturer's protocol with ExoSAP-IT (USB Corporation, Cleveland, $\mathrm{OH}$ ) then were subjected to a cycle sequencing reaction using the Big Dye Terminator v3.1 Cycle Sequencing kit (Applied Biosystems, Foster City, CA) according to manufacturer's protocol. Products were purified with Performa DTR Ultra 96well plates (Edge Biosystems, Gaithersburg, MD) in order to remove excess dye terminators. Samples were sequenced on an ABI Prism 3100 DNA sequencer (Applied Biosystems, Foster City, CA). Electropherograms generated from the ABI Prism 3100 were analyzed using the Lasergene DNA and protein analysis software (DNASTAR, Inc., Madison, WI). Electropherograms were read by two independent evaluators without knowledge of the subject's disease status. All patients were sequenced in the forward direction ( 5 ' to $3^{\prime}$ ), unless variants or polymorphisms were identified, in which case confirmation was obtained in some cases by sequencing in the reverse direction.

\section{Statistical Analyses}

Statistical analysis was performed using the R and STATA (v8) packages. The McNemar's test was used to evaluate the effect of each SNP individually on risk of AMD. First the standard $2 \times 2$ table was constructed, and then a modification of the McNemar's test using a $3 \times 3$ table, $T_{1}=\frac{(|b-c|+1)^{2}}{b+c}$ was also employed to compare the effect of the three genotypes for each variant simultaneously. A Bonferroni correction was applied to all resulting $P$ values

Table 4: Subject Characteristics

\begin{tabular}{ccccc}
\hline Population & Mean Age (years) & Range & Standard Deviation & \% Male (n/I34) \\
\hline Affected Siblings & 71.28 & $48.97-86.38$ & 8.26 & $45.5 \%(61 / 134)$ \\
Unaffected Siblings & 72.77 & $41.32-90.86$ & 8.97 & $39.6 \%(53 / 134)$
\end{tabular}


Table 5: PCR Conditions

\begin{tabular}{llllll}
\hline SNPs & Gene & Location & Variant & Forward primer & Reverse Primer \\
\hline rs 11575221 & $?$ & $?$ & A/C & TCTCCAGGCTCCTCAAGCTA & CGCCTACAACTTCGGCTAAC \\
rs 949252 & GPRI52 & Exon 0I & T/C & CAGCCACAGCTGAACCCTAC & TCTGACTGGCTGGTTCCTCT \\
rs 11194995 & ADD3 & Intron I2 & C/T & TCAAGAGTGTTTTCTTCCCATTT & ATTAGTCGGGCACGGTGA \\
rs6656448 & ZBTB4I & Intron 02 & G/A & ATTAACACGCCTCCAACCAC & CAACAGTGTTTGGGCTGAGA \\
rs 12677 & ASPM & 3' UTR & C/T & GGGAAATGATGTGTTCAGGAG & AGGTGTAATCAGCTATTATTTCCTTT \\
rs6003 & FI3B & Exon I0 & G/A & TCCAAAATGAAATCGCCAAT & GGTGGGTTGTAGGGATTGAG \\
\hline
\end{tabular}

Abbreviations: PCR, Polymerase Chain Reaction; SNP, Single Nucleotide Polymorphism.

that were calculated for each allele of the 35 SNPs that met these criteria. Linkage disequilibrium $\left(r^{2}\right)$ between adjacent SNPs on the same chromosome was evaluated. Both SNPHAP and Phase were used separately in cases and controls to reconstruct the diplotype (haplotype pair) for each sample in each SNP group. The posterior probability for any of the resulting diplotypes was calculated. The diplotype with the largest probability ( $>0.80$ for all of the samples) was picked up as the designated diplotype. For haplotype analysis, SNPs that fit the following criteria were analyzed: selected SNPs on the same chromosome, adjacent SNPs in statistically significant LD, and minor allele frequencies were similar. Both types of McNemar's tests were then used to determine significant haplotypes. Conditional logistic regression (CLR) was performed to identify factors associated with neovascular AMD. Potential risk factors, SNPs, were evaluated initially one at a time. Any significant allelic factors were then tested for significance while controlling for age, gender and smoking history. For each significant SNP, the minor allele (in unaffected siblings) in both the homozygous and heterozygous states versus the common allele in the homozygous state was examined in the model. Gene-gene interaction was tested first by assuming each locus had two alleles, with three possible genotypes and 9 possible two-locus genotypes. The likelihood ratio test (LRT) was used to test the null hypothesis of no gene-gene interaction (logarithm of odds ratio $=0$ ). Three genotypic models were examined (Additive, Dominant, and Recessive) using the likelihood ratio test.

Genotype and allele frequencies for all SNPs identified as significant were calculated in the affected and separately in unaffected siblings [see Additional File 1]. Deviation from Hardy-Weinberg Equilibrium (HWE) was tested on each SNP in unaffected (control) individuals using the chi square test.

\section{Competing interests}

The authors declare that they have no competing interests.

\section{Authors' contributions}

$\mathrm{HZ}$ participated in the design of the study, performed the statistical analysis and helped to draft the manuscript. AD participated in the design of the study and performed the statistical analysis. MAM carried out the molecular genetic studies, participated in the sequence alignment, Sequenom analysis and helped to draft the manuscript. SA, MA, $\mathrm{NH}, \mathrm{MR}, \mathrm{AB}$ carried out the molecular genetic studies, participated in the sequence alignment and Sequenom analysis. JWM, IKK participated in the design of the study, recruited and characterized patients. JH conceived of the study, participated in its design and coordination, performed the statistical analysis and helped to draft the manuscript. MMD conceived of the study, participated in its design and coordination, recruited and characterized patents, carried out the molecular genetic studies, participated in the sequence alignment, Sequenom analysis and helped to draft the manuscript. All authors read and approved the final manuscript.

\section{Additional material}

\section{Additional file 1}

"Genotype and Allele Frequencies", is a word file containing the genotype and allele frequencies of all the SNPs genotyped.

Click here for file

[http://www.biomedcentral.com/content/supplementary/14712350-9-51-S1.doc]

\section{Acknowledgements}

This study was supported by grants from the Ruth and Milton Steinbach Fund, the Lincy Foundation, the Massachusetts Lions, Friends of the Massachusetts Eye and Ear Infirmary, Genetics of Age-related Macular Degeneration Fund, MEEl, Research to Prevent Blindness, Marion W. and Edward F. Knight AMD Fund, Fight for Sight and NIH grants EYOI 4458 and EY I4IO4.

\section{References}

I. The Eye Diseases Prevalence Research Group: Prevalence of AgeRelated Macular Degeneration. Archives of Ophthalmology 2004, 1 22:564-574.

2. National Eye Institute (NEI) Age-Related Eye Disease Study (AREDS) 2007 [http://www.ncbi.nlm.nih.gov/projects/gap/cgi-bin/ study.cgi?id=phs00000I]. 
3. Mailman MD, Feolo M, jin Y, Kimura M, Tryka K, Bagoutdinov R, Hao L, Kiang A, Paschall J, Phan L, Popova N, Pretel S, Ziyabari L, Lee M, Shao Y, Wang ZY, Sirotkin K, Ward M, Kholodov M, Zbicz K, Beck J, Kimelman M, Shevelev S, Preuss D, Yaschenko E, Graeff A, Ostell J, Sherry ST: The NCBI dbGaP database of genotypes and phenotypes. Nat Genet 2007, 39: I I8I-I I86.

4. Risch $\mathrm{N}$, Zhang $\mathrm{H}$ : Extreme discordant sib pairs for mapping quantitative trait loci in humans. Science 1995, 268:1584-1589. 5. Bird AC, Bressler NM, Bressler SB, Chisholm IH, Coscas G, Davis MD, De Jong PTVM, Klaver CCW, Klein BEK, Mitchell P, Sarks JP, Sarks SH, Soubrane G, Taylor HR, Vingerling JR: An international classification system and grading system for age-related maculopathy and age-related macular degeneration. Surv Ophthalmol 1995, 39:367-374.

6. Klein R, Klein BE, Linton KL: Prevalence of age-related maculopathy. The Beaver Dam Eye Study. Ophthalmology 1992, 99:933-943.

7. Klein R, Klein BE, Knudtson MD, Wong TY, Cotch MF, Liu K, Burke G, Saad MF, Jacobs DR Jr.: Prevalence of age-related macular degeneration in 4 racial/ethnic groups in the multi-ethnic study of atherosclerosis. Ophthalmology 2006, I I 3:373-380.

8. Friedman DS, O'Colmain BJ, Munoz B, Tomany SC, McCarty C, de Jong PT, Nemesure B, Mitchell P, Kempen J: Prevalence of agerelated macular degeneration in the United States. Arch Ophthalmol 2004, I 22:564-572.

9. Vingerling JR, Dielemans I, Hofman A, Grobbee DE, Hijmering M, Kramer CFL, De Jong PTVM: The Prevalence of Age-related Maculopathy in the Rotterdam Study. Ophthalmology 1995, 102:205-210.

10. Mitchell P, Smith W, Attebo K, Wang JJ: Prevalence of age-related maculopathy in Australia. The Blue Mountains Eye Study. Ophthalmology 1995, 102: 1450-1460.

II. Risch NJ, Zhang H: Mapping quantitative trait loci with extreme discordant sib pairs: sampling considerations. $\mathrm{Am} J$ Hum Genet 1996, 58:836-843.

12. Boehnke M, Langefeld CD: Genetic association mapping based on discordant sib pairs: the discordant-alleles test. Am J Hum Genet 1998, 62:950-961.

13. DeAngelis MM, Ji F, Kim IK, Adams S, Capone A Jr., Ott J, Miller JW, Dryja TP: Cigarette smoking, CFH, APOE, ELOVL4, and risk of neovascular age-related macular degeneration. Arch Ophthalmol 2007, I 25:49-54.

14. DeAngelis MM, Ji F, Adams S, Morrison MA, Harring AJ, Sweeney MO, Capone A Jr., Miller JW, Dryja TP, Ott J, Kim IK: Alleles in the HtrA Serine Peptidase I Gene Alter the Risk of Neovascular Age-Related Macular Degeneration. Ophthalmology 2007.

15. ENSEMBL Genome Browser 2007 [http://www.ensembl.org/ Homo sapiens/geneview?gene].

16. Shuler RK Jr., Hauser MA, Caldwell J, Gallins P, Schmidt S, Scott WK, Agarwal A, Haines JL, Pericak-Vance MA, Postel EA: Neovascular age-related macular degeneration and its association with LOC 3877 I 5 and complement factor $\mathrm{H}$ polymorphism. Arch Ophthalmol 2007, I 25:63-67.

17. Dewan A, Liu M, Hartman S, Zhang SS, Liu DT, Zhao C, Tam PO, Chan WM, Lam DS, Snyder M, Barnstable C, Pang CP, Hoh J: HTRA I promoter polymorphism in wet age-related macular degeneration. Science 2006, 314:989-992.

18. Yang Z, Camp NJ, Sun H, Tong Z, Gibbs D, Cameron DJ, Chen H, Zhao Y, Pearson E, Li X, Chien J, Dewan A, Harmon J, Bernstein PS, Shridhar V, Zabriskie NA, Hoh J, Howes K, Zhang K: A variant of the HTRAI gene increases susceptibility to age-related macular degeneration. Science 2006, 3 14:992-993.

19. Klein RJ, Zeiss C, Chew EY, Tsai JY, Sackler RS, Haynes C, Henning AK, SanGiovanni IP, Mane SM, Mayne ST, Bracken MB, Ferris FL, Ott J, Barnstable C, Hoh J: Complement factor $\mathbf{H}$ polymorphism in age-related macular degeneration. Science 2005, 308:385-389.

20. Haines JL, Hauser MA, Schmidt S, Scott WK, Olson LM, Gallins P, Spencer KL, Kwan SY, Noureddine M, Gilbert JR, Schnetz-Boutaud N, Agarwal A, Postel EA, Pericak-Vance MA: Complement factor $\mathbf{H}$ variant increases the risk of age-related macular degeneration. Science 2005, 308:419-42I

21. Edwards AO, Ritter R III, Abel KJ, Manning A, Panhuysen C, Farrer LA: Complement factor $\mathbf{H}$ polymorphism and age-related macular degeneration. Science 2005, 308:42I-424.

22. Zareparsi S, Branham KE, Li M, Shah S, Klein RJ, Ott J, Hoh J, Abecasis $\mathrm{GR}$, Swaroop A: Strong association of the $\mathrm{Y402H}$ variant in complement factor $\mathbf{H}$ at Iq32 with susceptibility to agerelated macular degeneration. Am J Hum Genet 2005, 77:149-153.

23. Hageman GS, Anderson DH, Johnson LV, Hancox LS, Taiber AJ, Hardisty LI, Hageman JL, Stockman HA, Borchardt JD, Gehrs KM, Smith RJ, Silvestri G, Russell SR, Klaver CC, Barbazetto I, Chang S, Yannuzzi LA, Barile GR, Merriam JC, Smith RT, Olsh AK, Bergeron J, Zernant J, Merriam JE, Gold B, Dean M, Allikmets R: A common haplotype in the complement regulatory gene factor $H$ (HFI/CFH) predisposes individuals to age-related macular degeneration. Proc Natl Acad Sci U S A 2005, I 02:7227-7232.

24. Maller J, George S, Purcell S, Fagerness J, Altshuler D, Daly MJ, Seddon JM: Common variation in three genes, including a noncoding variant in $\mathrm{CFH}$, strongly influences risk of age-related macular degeneration. Nat Genet 2006, 38:1055-1059.

25. Hughes AE, Orr N, Esfandiary H, az-Torres M, Goodship T, Chakravarthy U: A common CFH haplotype, with deletion of CFHR I and CFHR3, is associated with lower risk of age-related macular degeneration. Nat Genet 2006, 38: I I73-1 I 77.

26. Komanasin N, Catto AJ, Futers TS, van H V, Rosendaal FR, Ariens RA A novel polymorphism in the factor XIII B-subunit (His95Arg): relationship to subunit dissociation and venous thrombosis. J Thromb Haemost 2005, 3:2487-2496.

27. Rodriguez de CS, Rey-Campos J, Dykes DD, McAlpine PJ, Wong P, Rubinstein P: Coagulation factor XIII B subunit is encoded by a gene linked to the regulator of complement activation (RCA) gene cluster in man. Immunogenetics 1988, 28:452-454.

28. Nonaka M, Matsuda Y, Shiroishi T, Moriwaki K, Nonaka M, Natsuume-Sakai S: Molecular cloning of the b subunit of mouse coagulation factor XIII and assignment of the gene to chromosome I: close evolutionary relationship to complement factor H. Genomics 1993, 15:535-542.

29. Rey-Campos J, Rubinstein P, Rodriguez de CS: A physical map of the human regulator of complement activation gene cluster linking the complement genes CRI, CR2, DAF, and C4BP. J Exp Med 1988, 167:664-669.

30. Bond J, Roberts E, Mochida GH, Hampshire DJ, Scott S, Askham JM, Springell K, Mahadevan M, Crow YJ, Markham AF, Walsh CA, Woods CG: ASPM is a major determinant of cerebral cortical size. Nat Genet 2002, 32:316-320

31. Kumar A, Blanton SH, Babu M, Markandaya M, Girimaji SC: Genetic analysis of primary microcephaly in Indian families: novel ASPM mutations. Clin Genet 2004, 66:34I-348.

32. Gul A, Tariq M, Khan MN, Hassan MJ, Ali G, Ahmad W: Novel protein-truncating mutations in the ASPM gene in families with autosomal recessive primary microcephaly. J Neurogenet 2007, 21:153-163.

33. Horvath S, Zhang B, Carlson M, Lu KV, Zhu S, Felciano RM, Laurance MF, Zhao W, Qi S, Chen Z, Lee Y, Scheck AC, Liau LM, Wu H, Geschwind DH, Febbo PG, Kornblum HI, Cloughesy TF, Nelson SF, Mischel PS: Analysis of oncogenic signaling networks in glioblastoma identifies ASPM as a molecular target. Proc Natl Acad Sci U S A 2006, 103: 17402-17407.

34. Caceres A, Mautino J, Kosik KS: Suppression of MAP2 in cultured cerebellar macroneurons inhibits minor neurite formation. Neuron 1992, 9:607-618.

35. Johnson GV, Jope RS: The role of microtubule-associated protein 2 (MAP-2) in neuronal growth, plasticity, and degeneration. J Neurosci Res 1992, 33:505-5 I2.

36. Mukai M, Hayashi Y, Kitadate Y, Shigenobu S, Arita K, Kobayashi S: MAMO, a maternal BTB/POZ-Zn-finger protein enriched in germline progenitors is required for the production of functional eggs in Drosophila. Mech Dev 2007, $124: 570-583$.

37. Tissing W], den Boer ML, Meijerink JP, Menezes RX, Swagemakers S, van der Spek PJ, Sallan SE, Armstrong SA, Pieters R: Genomewide identification of prednisolone-responsive genes in acute lymphoblastic leukemia cells. Blood 2007, 109:3929-3935.

38. Bilic I, Ellmeier W: The role of BTB domain-containing zinc finger proteins in $\mathrm{T}$ cell development and function. Immunol Lett 2007, 108: I-9.

39. DeAngelis MM, Lane AM, Shah CP, Ott J, Dryja TP, Miller JW: Extremely discordant sib-pair study design to determine risk factors for neovascular age-related macular degeneration. Arch Ophthalmol 2004, I 22:575-580.

40. Primer3 2007 [http://primer3.sourceforge.net/] 


\section{Pre-publication history}

The pre-publication history for this paper can be accessed here:

http://www.biomedcentral.com/1471-2350/9/51/prepub

Publish with Bio Med Central and every scientist can read your work free of charge

"BioMed Central will be the most significant development for disseminating the results of biomedical research in our lifetime. " Sir Paul Nurse, Cancer Research UK

Your research papers will be:

- available free of charge to the entire biomedical community

- peer reviewed and published immediately upon acceptance

- cited in PubMed and archived on PubMed Central

- yours - you keep the copyright 